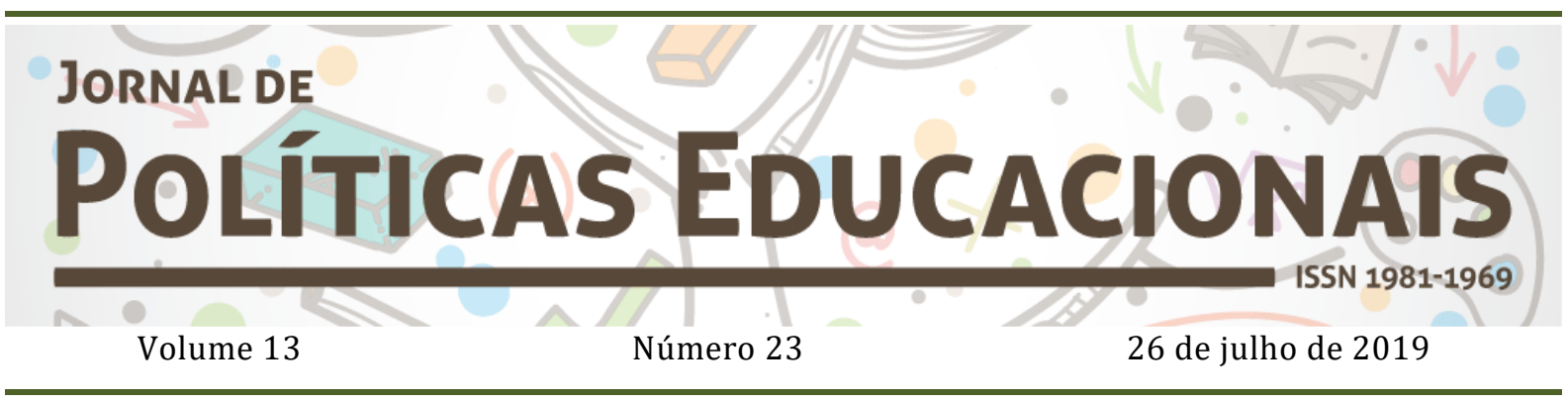

\title{
A participação nos Conselhos Municipais de Educação: entre limitações e potencialidades
}

\section{Participation in Municipal Councils of Education: between limitations and potentialities}

\section{La participación en los Consejos Municipales de Educación: entre limitaciones y potencialidades}

Andréia Vicência Vitor Alves' Elis Regina dos Santos Viegas ${ }^{2}$

Citação: ALVES, A. V. V.; VIEGAS, E. R. dos S. A participação nos Conselhos Municipais de Educação: entre limitações e potencialidades. Jornal de Políticas Educacionais. V. 13, n. 23. Julho de 2019.

\begin{abstract}
Resumo:
Este texto tem como intuito apreender a ideia e o potencial de participação no Conselho Municipal de Educação, uma vez que esta se constitui em um dos mecanismos democratizantes centrais da gestão educacional. Para tanto, foi realizado um estudo de natureza teórico-bibliográfica no sentido de evidenciar os Conselhos como espaços que apresentam dinâmica de participação diferenciada. Inferimos, portanto, a partir do estudo desenvolvido, que a participação no âmbito dos Conselhos Municipais de Educação tem como potencial a democratização da gestão educacional, por possibilitar a descentralização do poder, a promoção da transparência, o envolvimento e o trabalho coletivo, articulado e interativo, buscando fazer com que os cidadãos se tornem parte e tomem parte das decisões, visando garantir a efetividade de uma educação que atenda aos interesses da sociedade como um todo, em particular, das camadas mais desfavorecidas. Contudo, tais potencialidades (de participação) ocupam um espaço em sua essência e/ou raiz, em grande parte, no mundo ideal da legislação, já seus limites, por outro lado, estão situados no mundo real. Por isso, há necessidade iminente de um posicionamento coletivo crítico constante de defesa desse formato na gestão educacional pública.
\end{abstract}

Palavras-chaves: Gestão Democrática. Participação. Conselho Municipal de Educação.

\footnotetext{
1 Doutora em Educação (UFMS). Professora adjunta da FAED/UFGD. Orcid: https://orcid.org/0000-00025179-4053 Email: andreiaalves@ufgd.edu.br

2 Doutora em Educação (UFGD). Professora da REME Dourados-MS e da FAED/UFGD. Orcid: https://orcid.org/0000-0002-9557-3471 Email: elisreginaviegas@gmail.com
} 
ALVES, A. V. V.; VIEGAS, E. R. dos S. A participação nos Conselhos Municipais de Educação: entre limitações e potencialidades.

\begin{abstract}
The purpose of this text is to apprehend the idea and potential of participation in the Municipal Council of Education, since it constitutes one of the central democratizing mechanisms of educational management. For that, a theoretical-bibliographic study was carried out in order to highlight the Councils as spaces that present a dynamic of differentiated participation. We infer, therefore, from the developed study that participation in the scope of the Municipal Councils of Education has the potential to democratize educational management by enabling the decentralization of power, promoting transparency, involvement and collective work, articulated and interactive, aiming to make citizens become part of and take part in decisions in order to ensure the effectiveness of an education that serves the interests of society as a whole, in particular, the most disadvantaged. However, such potentialities (of participation) occupy a space in their essence and/or root, to a great extent, in the ideal world of legislation, since its limits, on the other hand, are situated in the real world. Therefore, there is an imminent need for a constant critical collective positioning to defend this format in public educational management.
\end{abstract}

Keywords: Democratic management. Participation. Municipal Council of Education.

\title{
Resumen:
}

Este texto tiene como intuición aprehender la idea y el potencial de participación en el Consejo Municipal de Educación, ya que ésta se constituye en uno de los mecanismos democratizantes centrales de la gestión educativa. Para ello, se realizó un estudio de naturaleza teórico-bibliográfica en el sentido de evidenciar los Consejos como espacios que presentan una dinámica de participación diferenciada. Por lo tanto, a partir del estudio desarrollado, la participación en el ámbito de los Consejos Municipales de Educación tiene como potencial la democratización de la gestión educativa, por posibilitar la descentralización del poder, la promoción de la transparencia, la participación y el trabajo colectivo, articulado e interactivo, que busca hacer que los ciudadanos se conviertan y tomen parte de las decisiones para garantizar la efectividad de una educación que atienda los intereses de la sociedad como un todo, en particular, de las capas más desfavorecidas. Sin embargo, tales potencialidades (de participación) ocupan un espacio en su esencia y/o raíz, en gran parte, en el mundo ideal de la legislación, ya sus límites, por otro lado, están situados en el mundo real. Por eso, hay necesidad inminente de un posicionamiento colectivo crítico constante de defensa de ese formato en la gestión educativa pública.

Palabras claves: Gestión Democrática. Participación. Consejo Municipal de Educación.

\section{Introdução}

A democratização educacional no Brasil ainda é um grande impasse não superado, a exemplo da universalização de vagas nos diferentes níveis e modalidades, o que demanda, para além do ingresso, oportunidades contínuas de permanência e manutenção com qualidade. Tal questão, até este momento, não foi solucionada e nos parece que está longe de ser, por envolver diversos gargalos, "seja pelo seu financiamento - que não prima por um padrão de qualidade social - seja pelo controle centralizado do planejamento educacional, seja pelas dificuldades de implementação da gestão colegiada, seja pela não participação dos sujeitos envolvidos na educação", como também "pela cultura da descontinuidade de programas educacionais dos governos que se sucedem" (BOSCO, 2011, p. 16). Esses elementos, dentre outros, tanto requerem como demanda urgente o fortalecimento de grupos e/ou instâncias de discussão, deliberação e decisão quanto os argumentos de defesa da educação pública educacional.

Essa discussão encontra-se mais atual do que nunca, em razão da "curvatura histórica momentânea" vivenciada, por conta do retrocesso em termos de avanços 
ALVES, A. V. V.; VIEGAS, E. R. dos S. A participação nos Conselhos Municipais de Educação: entre limitações e potencialidades.

democráticos de direito social, o qual "mais uma vez beneficia uma aristocracia brasileira modernizada, subserviente ao capital internacional” e que, por isso mesmo, torna-se fundante "não tergiversar para buscar a sobrevivência dos nossos ideais humanitários" (SANFELICE, 2017, p. 7).

Nesse horizonte, os Conselhos de Educação se constituem em um importante mecanismo de promoção, manutenção e resistência para a democratização da educação no nosso país. Observa-se que existem Conselhos de Educação no Brasil desde o Império, mas apenas com um caráter consultivo (e não deliberativo e normativo), que atuavam no âmbito das diretrizes e políticas educacionais.

Com o movimento progressista pela democratização da sociedade, da educação e pela participação direta na defesa de seus interesses nos processos decisórios de políticas públicas na década de 1980, houve a intensificação da participação social a partir desses Conselhos nas políticas públicas, firmada com a promulgação da Constituição Federal Brasileira (CF/1988), em razão desta garantir como fundamentos do sistema de governo do país a soberania e a cidadania.

O contexto do processo de democratização da gestão pública passou a requerer dos conselhos de educação nova configuração em sua natureza: a passagem de órgãos técnicos de governo para o exercício de funções de Estado. Fundados nas novas categorias de pertencimento e participação, os conselhos se tornam a expressão de uma institucionalidade cidadã e passam a representar, hoje, uma estratégia privilegiada de democratização das ações do Estado (BORDIGNON, 2017, p. 25).

Desta feita, a participação social tornou-se um direito e os conselhos se tornaram um espaço de implementação e ampliação participativa na gestão da administração pública, sendo considerados uma inovação institucional relevante no âmbito das políticas sociais, visto que, até então, a normatização do processo de ensino que estabelece as bases para o seu acompanhamento e avaliação era realizada por organizações hierárquicas e burocráticas.

Com a promulgação da Lei no 9.394 de 1996, que estabelece a Lei de Diretrizes e Bases da Educação Nacional (LDB), os municípios passaram a ter autonomia para organizar seus sistemas de ensino, que, quando democráticos, possibilitam a participação da sociedade na definição das políticas educacionais por intermédio da participação direta e da participação representativa no Conselho Municipal de Educação.

Tais Conselhos podem ser espaços que apresentam dinâmica de participação, de abertura e de diálogo a serviço da educação, cooperando com o zelo da aprendizagem e 
ALVES, A. V. V.; VIEGAS, E. R. dos S. A participação nos Conselhos Municipais de Educação: entre limitações e potencialidades.

defendendo o interesse coletivo, constitui-se numa instituição importante para a efetiva democratização da gestão educacional, por ocupar espaços cada vez maiores no âmbito da organização educacional pública. Como afirma Lima (2011, p. 31), "a democratização se constitui em um instrumentalizador de lutas sociais, políticas e econômicas", pois a conquista de direitos, já efetivamente garantidos e usufruídos, permite a construção da base legal e social de busca por sua extensão.

Assim, por meio de estudo teórico-bibliográfico, buscamos apreender a compreensão de participação no Conselho Municipal de Educação, uma vez que esta se constitui em um dos mecanismos basilares da gestão educacional e, consequentemente, dos Conselhos de Educação.

Num primeiro momento, apresentamos brevemente a concepção de gestão democrática da educação e a participação como um de seus mecanismos. A seguir, abordamos os Conselhos de Educação, em especial, o Conselho Municipal de Educação e, logo após, a participação nessa instância; e, por fim, as considerações finais.

\section{A participação como mecanismo de gestão democrática da educação}

A democratização da educação é essencial para a qualidade socialmente referenciada da educação ${ }^{3}$, por ter em vista o ser humano, a emancipação e a transformação social. Conforme Alves (2014, p. 21), a gestão democrática da educação é "um processo de caráter político-pedagógico e administrativo no qual se dá a participação efetiva da sociedade em todos os níveis de decisão e execução da atividade educativa, com real poder de interferência e manifestação".

Em âmbito legal, Gracindo (2007) esclarece que a gestão democrática é um princípio previsto na CF/1988 e reafirmado na LDB/1996, que inicialmente se propõe a exercitar a democracia participativa em esfera restrita - escolas, universidades, conselhos, grêmios, comunidades e órgãos públicos em geral -, mas que pode contribuir progressivamente para a própria democratização da sociedade como um todo.

Essa proposta de gestão busca a descentralização do poder, o diálogo, o trabalho coletivo, a valorização da maneira de ser, pensar e agir dos cidadãos, e o crescimento deles

\footnotetext{
${ }^{3}$ Visa à emancipação dos sujeitos sociais e não guarda em si mesma um conjunto de critérios que a delimite. Pelo contrário, a "educação de qualidade" referenciada no social é aquela que contribui com a formação dos estudantes nos aspectos culturais, antropológicos, econômicos e políticos, para o desempenho de sua cidadania no mundo (BRASIL, 2014, p. 52).
} 
ALVES, A. V. V.; VIEGAS, E. R. dos S. A participação nos Conselhos Municipais de Educação: entre limitações e potencialidades.

como cidadãos, e da sociedade enquanto sociedade democrática, ao apresentar-se como um de seus mecanismos basilares a participação.

De acordo com Paro (2002), quando se fala a respeito da participação ainda falta algo, porque o termo participação não está só na execução, envolve a participação em todo o processo (começo, meio e fim), assumindo, portanto, a democracia - enquanto valor universal e prática de nuances recíprocas entre grupos e pessoas, ação "globalizante" que, tendencialmente, deve envolver cada indivíduo -, pois não há "democracia plena sem pessoas democráticas para exercê-la" (PARO, 2002, p. 25). Ou seja, é essencial que a prática social e a das instituições, em especial as públicas, sejam de cultura democrática.

Assim compreendido, tal formato apresenta a participação como uma oportunidade para que os cidadãos façam parte do poder decisório, pela via argumentativa no espaço público, em que são ajustadas reciprocamente as posições dos interlocutores até que se cristalize um consenso, tomando-se decisões de acordo com a vontade da maioria.

Pode, também, permitir que os cidadãos façam parte desse processo pelo diálogo, que põe no centro/priorize a vontade e os anseios de comunidades, tendo os cidadãos voz e vez no processo de decisão que lhes dizem respeito; e/ou, ainda, pela decisão da maioria, em que se elegem representantes para se posicionar e defender os seus interesses, nas situações em que não há participação direta no processo de discussão e decisão.

Desta feita, como mecanismo da gestão democrática da educação, a participação no formato que defendemos proporciona e amplia a atuação consciente em todos os níveis de decisão e execução da educação; fomenta a descentralização do poder; viabiliza a avaliação das políticas educacionais e dos processos de aprendizagem; promove a transparência; suscita o trabalho coletivo, articulado e interativo; motiva a cooperação; imprime o respeito aos direitos dos cidadãos, no que se refere à maneira de ser, agir e pensar; possibilita a inclusão social; incentiva a cidadania crítica, por meio da transformação e emancipação social; garante a liberdade de expressão, por intermédio da igualdade de presença e de direito. Sendo todos esses aspectos materializados pela eleição de dirigentes; órgãos colegiados; autonomia didático-científico, administrativa e de gestão financeira e patrimonial; além da tão almejada democratização da aprendizagem.

Tal participação propicia aos indivíduos tomarem parte de um poder, tendo seus interesses, suas vontades e seus valores levados em conta, constituindo-se em um 
ALVES, A. V. V.; VIEGAS, E. R. dos S. A participação nos Conselhos Municipais de Educação: entre limitações e potencialidades.

processo de aprendizagem do poder cotidianamente nos espaços e momentos em que se esteja vivendo e atuando.

Segundo Motta (2003), a "autêntica participação" é considerada o ato de participar de um poder (tomar parte de) com desejo e um alto grau de envolvimento individual ou coletivo em atividades políticas, contribuindo constantemente para o seu aprimoramento.

Sendo assim, significa uma intervenção dos cidadãos no planejamento, na deliberação, no exercício, na fiscalização da atuação e/ou na vontade dos grupos ou entidades/associações a que pertencem; com vistas a exprimir seus desejos e valores, de forma consciente, discutindo e tomando decisões por meio de debates, que devem estar de acordo com os interesses da coletividade, havendo, desse modo, constante interação entre os diferentes atores que se constituem partes, o Estado, outras instituições políticas e a própria sociedade em sua totalidade.

Motta (2003) afirma ser possível participar de um poder com mecanismos de influência sobreele, mas acredita ser difícil dizer até que ponto as pessoas participam efetivamente na tomada e na implementação das decisões que dizem respeito à coletividade, e até que ponto são manipuladas. São muito fortes as relações de força e poder, na participação, já que esta constitui-se em um tema complexo, com forte conteúdo político-ideológico.

Muitas pessoas preferem não participar por não ter consciência de como a sua participação é importante e, em geral, por terem sido educadas em contextos muito autoritários. Motta (2003), menciona quatro formas de participação: conflitual, funcional, administrativa e cogestão; e, ainda, distingue participação de autogestão. Já Nogueira (2004) fala da participação a partir de quatro modalidades: assistencialista, corporativa, eleitoral e política. Contudo, neste estudo abordaremos apenas os modelos de participação direta e indireta ou representativa, considerados modelos centrais de organização política democrática, sendo os efetivados com maior frequência no âmbito educacional.

Na participação direta, as decisões políticas devem ser tomadas por aqueles que estarão submetidos a elas por meio do debate público, sendo de incumbência dos cidadãos, no seu conjunto, a definição e autorização das decisões políticas. Nesta, o poder emana do povo, tendo em conta que compete aos cidadãos a participação nos processos de discussão e de decisão. Na educação, esse modelo pode ser materializado na gestão escolar, possibilitando a participação da comunidade interna e externa nas discussões e 
ALVES, A. V. V.; VIEGAS, E. R. dos S. A participação nos Conselhos Municipais de Educação: entre limitações e potencialidades.

deliberações no âmbito educacional conforme seus interesses com real poder de interferência.

Já na participação indireta ou representativa, a responsabilidade do processo decisório fica restrita aos representantes escolhidos pelo sufrágio eleitoral, que devem atuar conforme as demandas de seus representados. Nesta, a participação pode ser efetivada na educação por meio da eleição de diretores, na qual a comunidade escolar e local vai eleger um representante para gerir a escola, e por meio dos Conselhos de Educação (Escolar, Associação de Pais e Mestres, Conselhos Nacional, Estadual e Municipal), em que são eleitos representantes para atuar de acordo com o direitos coletivos, sendo considerados um elo (CURY, 2006) entre o Estado e a sociedade. Para participar é imprescindível algum conhecimento e certas habilidades políticas adquiridas no próprio exercício de participação que possibilita experiência em tal processo que deve ser iniciado a qualquer tempo.

Nesse ponto, é importante destacar que a "iniciação" pode ocorrer pela via da educação participativa, que, conforme indicou Motta (1987, p. 203), estimula e agrega "habilidades de valor" por meio do "processo de aprendizagem democrática", uma vez que

[...] a criança aprenda a ser livre, sabendo respeitar e se fazendo respeitar, que aprenda a pensar com autonomia, a ser sincera, a ser capaz de amar e ser amada, que possa lutar pela promoção da pessoa humana, que possa criar uma consciência crítica e auto-crítica, que saiba se expressar e ser justa, que venha a possuir uma cultura verdadeira.

Aspecto reafirmado por Pateman (1992), a participação deve ser educativa e promover o desenvolvimento da cidadania como requisito central para a garantia da ruptura com o ciclo de subordinação e de injustiças sociais, por meio de um processo de formação e conscientização (individual e coletiva), que acarretaria em um processo fundado nas relações entre participação cidadã, mudança da consciência política e redução das desigualdades sociais.

A participação deve ser tratada como tema central nos encaminhamentos escolares por estudantes, pais, professores, gestores, coordenadores e demais profissionais da educação, bem como em outros espaços, em razão de ser imprescindível para a transformação humana e social, além de concorrer para a edificação de uma sociedade verdadeiramente igualitária, em termos econômicos, sociais e de distribuição de poder (MOTTA, 1987). "Participação, portanto, é a aprendizagem do poder em todos os momentos e lugares em que se esteja vivendo e atuando" (BRASIL, 2004, p. 27). 
ALVES, A. V. V.; VIEGAS, E. R. dos S. A participação nos Conselhos Municipais de Educação: entre limitações e potencialidades.

Nesse cenário, são considerados instrumentos da participação: o plebiscito, o referendo, as assembleias, a iniciativa popular de leis, as eleições, os conselhos gestores de políticas sociais, dentre outros. Ambos concorrem para o controle do Estado pela sociedade; portanto, controle social e político.

De acordo com Azevedo (2011), há a indicação da necessidade de que a construção de políticas de Estado, voltadas para a qualidade da educação socialmente referenciada para todos, deve ser respaldada por debates referentes

[...] à apreensão de um conjunto de variáveis que interfere no âmbito das relações sociais mais amplas, envolvendo questões macroestruturais, como concentração de renda, desigualdade social, garantia do direito à educação, dentre outras. Envolve, igualmente, questões concernentes à análise de sistemas e instituições de educação básica e superior, bem como ao processo de organização e gestão do trabalho educativo, que implica condição de trabalho, processos de gestão educacional, dinâmica curricular, formação e profissionalização. A educação é, assim, perpassada pelos limites e possibilidades da dinâmica pedagógica, econômica, social, cultural e política de uma dada sociedade (AZEVEDO, 2011, p. 48).

Destarte, um dos mecanismos da gestão educacional que possibilita a participação nas discussões e tomada de decisões nas questões macroestruturais são os Conselhos Municipais da Educação, que têm em vista a participação da comunidade escolar e local na política educacional no âmbito dos municípios - que pode se estender para o estadual e até nacional -, no intento de contribuir para a democratização do ensino e a efetivação de uma educação universal e de qualidade, que tenha em vista uma formação crítica e humana dos cidadãos.

\section{Os Conselhos Municipais de Educação}

Os Conselhos de Educação se constituem em uma junção entre sociedade política e a sociedade civil, que participam das tomadas de decisão quanto à gestão educacional, possibilitando a efetivação de uma gestão pautada no diálogo, na comunicação e na democracia, que visa uma ação participativa e descentralizada. Assim, os conselhos, dentre outros, o de educação, "têm como conceito fundamental a deliberação coletiva, formulada com base nos diferentes olhares da pluralidade social, nos diferentes pontos de vista, dos que fazem parte ou têm interesse em determinada área social ou organização que diz respeito à sua vida e da coletividade (BORDIGNON, 2017, p. 19).

A concepção de participação aqui construída e apresentada (MOTTA, 2003) se fundamenta na análise processual "de tomar parte" de uma atividade coletiva e que, 
ALVES, A. V. V.; VIEGAS, E. R. dos S. A participação nos Conselhos Municipais de Educação: entre limitações e potencialidades.

portanto, traz consigo a dimensão pública. Embora compreenda-se que participar é muito mais do que tomar conhecimento de uma questão/discussão, vai além da informação em si. Trata-se, segundo Oliveira (2003, p. 72), de uma relação em que o Conselho (mecanismo) é assumido como espaço participativo propício "de tomada de decisão e construção de mediação que inclui o cidadão historicamente excluído nas deliberações políticas e no controle social da gestão pública".

Para sua real efetivação, Gohn (2002, p. 25) considera o caminho da participação mediante o processo de qualificação, isto é, tomar conhecimento de modo referenciado sobre o funcionamento das dimensões e esferas a que diz respeito e não apenas "de integrá-los, incorporá-los simplesmente à teia burocrática". O espaço do Conselho demanda um conhecimento estrutural - Estado, sistema, políticas, programas e ações específicas - que permita o exercício da cidadania de forma ativa, o que demanda diálogo, debate e defesa, devidamente qualificada, do direito à educação.

Em outro momento, Gohn (2000) analisa alguns pontos/questões de reflexão que em sua opinião compõem e qualificam a ação dos Conselhos e que, por isso, devem ser apreendidos pelos sujeitos que transitam nestes espaços de gestão:

a) a constituição estrutural dos conselhos e sua natureza decisória. Qual é a forma em que foi (ou está sendo) organizado (deliberativa ou apenas conselheira/consultiva);

b) dada sua existência, qual a relação que estabelece entre o governo e a sociedade civil (principalmente com os movimentos sociais e com as entidades não governamentais);

c) quais as fronteiras entre sociedade e governo (poder local, basicamente);

d) qual a forma de combinação entre a democracia direta e indireta nos conselhos (GOHN, 2000, p. 182).

Nesse processo de busca pela compreensão, discussão e atuação dos Conselhos, a participação, efetivamente ativa, qualifica e posiciona o cidadão de acordo com o que Oliveira (2003) nomeia de "sujeito social coletivo", conferindo-lhe um caráter político transformador, que destaca e potencializa a participação como fonte inesgotável de emancipação. Assim, a participação nos Conselhos Municipais de Educação - que dialoga com as questões macro e micro das políticas públicas nos processos de escolha de prioridades locais - pode se tornar exemplo de atuação "política transformadora da cultura participativa local e da construção da democracia em suas diversas dimensões" (OLIVEIRA, 2003, p. 73).

Com tais características, os Conselhos Municipais de Educação concorrem para a democratização da educação, podendo se tornar espaço de articulação política, de 
ALVES, A. V. V.; VIEGAS, E. R. dos S. A participação nos Conselhos Municipais de Educação: entre limitações e potencialidades.

organização e de reflexão da sociedade civil no que concerne aos problemas educacionais no âmbito local, estadual e nacional.

$\mathrm{Na}$ essência, todos os espaços ${ }^{4}$ vinculados ao campo da educação pública convergem para a garantia do acesso, e a permanência de todos, ao espaço público educacional de qualidade. Assume-se assim, obrigatoriamente, que a educação (Art.206, CF/1988) é um "serviço público e de finalidade universal" e, portanto, sua oferta "deve ser cuidadosamente gerida a fim de que a igualdade perante a lei, a igualdade de condições e de oportunidades tenham vigência para todos, sem distinção" (CURY, 2006, p. 45).

De tal modo, parte-se do entendimento de que os Conselhos Municipais de Educação, bem como os estaduais e o nacional, "são órgãos colegiados, de caráter normativo, deliberativo e consultivo que interpretam e resolvem, segundo suas competências e atribuições, a aplicação da legislação educacional" (CURY, 2006, p. 44).

Nesse horizonte, os Conselhos têm ocupado espaços cada vez maiores no âmbito da organização educacional, como espaço de diálogo coletivo de representação da sociedade civil, em que se apresentam alternativas, ponderações, encaminhamentos, bem como decisões em matéria de ação no âmbito de sua competência.

Essa postura exige uma tomada de responsabilidade no que diz respeito ao controle das ações "quanto à garantia do direito à educação materializada no direito à aquisição e desenvolvimento de aprendizagens", devendo ser, portanto, objetivo central na construção da agenda dos Conselhos Municipais de Educação (BRASIL, 2008, p. 16).

Estabelecido isso, cabe ao Conselho tomar como referência, além dos princípios constitucionais, os princípios e fins da educação, conforme afirmado na LDB/1996, isto é, "espera-se desse órgão o acompanhamento e o controle dos princípios constitucionais no que concerne ao ensino" (BRASIL, 2008, p. 17), tendo em vista aqueles reafirmados pela LDB (art. $3^{\circ}$, incisos I a XII) e aqueles que a ela foram acrescidos:

I - igualdade de condições para o acesso e permanência na escola;

II - liberdade de aprender, ensinar, pesquisar e divulgar a cultura, o pensamento, a arte e o saber;

III - pluralismo de ideias e de concepções pedagógicas;

IV - respeito à liberdade e apreço à tolerância;

$\mathrm{V}$ - coexistência de instituições públicas e privadas de ensino;

VI - gratuidade do ensino público em estabelecimentos oficiais;

VII - valorização do profissional da educação escolar;

VIII - gestão democrática do ensino público, na forma desta Lei e da legislação dos sistemas de ensino;

IX - garantia de padrão de qualidade;

\footnotetext{
${ }^{4}$ De classe, escolares, fiscal, social, tutelares, municipal, estadual, nacional, entre outros.
} 
ALVES, A. V. V.; VIEGAS, E. R. dos S. A participação nos Conselhos Municipais de Educação: entre limitações e potencialidades.

X - valorização da experiência extraescolar;

XI - vinculação entre a educação escolar, o trabalho e as práticas sociais;

XII - consideração com a diversidade étnico-racial (BRASIL, 1996).

Além disso, assumem-se outros itens que foram incorporados na agenda de controle e acompanhamento dos Conselhos na instância municipal, considerando o movimento de luta pela democratização da educação pública na atualidade: como o Fundo de Manutenção e Desenvolvimento da Educação Básica e de Valorização dos Profissionais da Educação (FUNDEB), instrumento que tem como potencial a melhoria das condições para a oferta e manutenção da educação básica; bem como ações que consideram a diversidade étnico-racial; com especial atenção, a educação multicultural e a modalidade da educação especial (artigos 58 e 59 da LDB/1996, com nova redação dada pelas Lei nำ12.796/2013 e Lei nำ13.632/2018); o debate sobre a ampliação e manutenção do ensino fundamental de nove anos (Lei no 11.274/2006), com início aos seis anos de idade e extensão até os quatorze anos; além da etapa da educação infantil - creche com progressivo atendimento infantil na faixa etária de zero a três anos e a obrigatoriedade do atendimento a toda população infantil na faixa etária de quatro a cinco anos de idade - que traz consigo especificidades e demandas (artigos 29, 30 e 31 da LDB/1996, com texto acrescido e atualizado pela Lei $\mathrm{n}^{\mathrm{o}} \mathrm{n}$ ำ12.796/2013), historicamente ainda não equacionadas; respeito e atenção aos aspectos e singularidades que perpassam todas essas questões e que derivam outras.

Tais inquietações devem ser direcionadas e atentadas diretamente à população que ingressa na educação básica - etapas e modalidades -, apreendendo sua movimentação (espaço, tempo e currículo) no ambiente escolar, com vistas à aprendizagem. "Na verdade, espera-se do Conselho um trabalho de política educacional e prática pedagógica, atento às práticas de exclusão-inclusão e de afirmação-negação da escola de qualidade social” (BRASIL, 2008, p. 17). Prerrogativa já afirmada por Cury (2006, p. 45), "Sua linha de frente é, dentro da relação Estado e Sociedade, estar a serviço das finalidades maiores da educação e cooperar com o zelo pela aprendizagem nas escolas brasileiras".

Nesse sentido, espera-se que o Conselho Municipal de Educação possa ser a instância de controle e deliberação do processo de implantação e efetivação de políticas e programas, atentando para a construção da proposta pedagógica que leve em consideração a discussão sobre a escola e o ensino. 
ALVES, A. V. V.; VIEGAS, E. R. dos S. A participação nos Conselhos Municipais de Educação: entre limitações e potencialidades.

Oliveira (2003) apresenta uma síntese que discorre sobre as potencialidades e limites que dizem respeito aos Conselhos enquanto órgãos de controle e acompanhamento das políticas públicas:

Quadro: Potencialidades e limites dos Conselhos

\begin{tabular}{|c|c|c|}
\hline Potencialidades & Limites & Saídas \\
\hline $\begin{array}{l}\text { Espaço institucional de } \\
\text { negociação entre sociedade } \\
\text { civil e o Estado. }\end{array}$ & $\begin{array}{l}\text { Fraca capacidade de } \\
\text { negociação dos conselheiros } \\
\text { da parte da sociedade civil. }\end{array}$ & $\begin{array}{l}\text { Mais investimento em } \\
\text { programas de capacitação dos } \\
\text { conselheiros. }\end{array}$ \\
\hline $\begin{array}{l}\text { Espaço que possibilita o } \\
\text { exercício do controle social } \\
\text { sobre a ação do Estado por } \\
\text { meio da ação da sociedade. }\end{array}$ & $\begin{array}{l}\text { Pouco conhecimento dos } \\
\text { conselheiros sobre } \\
\text { funcionamento das políticas } \\
\text { públicas e do Estado. }\end{array}$ & $\begin{array}{l}\text { Capacitação orientada para } \\
\text { lógica, natureza e } \\
\text { funcionamento das políticas } \\
\text { públicas e do Estado. }\end{array}$ \\
\hline $\begin{array}{l}\text { Possibilidade de domínio das } \\
\text { políticas públicas específicas: } \\
\text { saúde, educação, criança e } \\
\text { adolescente, assistência } \\
\text { social etc. } \\
\end{array}$ & $\begin{array}{l}\text { Fragmentação das políticas } \\
\text { públicas que levam os } \\
\text { conselhos a atuarem de } \\
\text { forma isolada e } \\
\text { desarticulada. }\end{array}$ & $\begin{array}{l}\text { Criação de fóruns municipais e } \\
\text { redes intermunicipais de } \\
\text { conselheiros; estruturas físicas } \\
\text { e infraestrutura compartilhada. }\end{array}$ \\
\hline $\begin{array}{l}\text { Capacidade de construção da } \\
\text { cidadania ativa por meio da } \\
\text { atuação eficiente. }\end{array}$ & $\begin{array}{l}\text { Baixa eficácia e eficiência } \\
\text { dos conselheiros. }\end{array}$ & $\begin{array}{l}\text { Desenvolver instrumentos de } \\
\text { planejamento e avaliação da } \\
\text { atuação dos conselhos e } \\
\text { conselheiros. }\end{array}$ \\
\hline $\begin{array}{l}\text { Espaço com possibilidade de } \\
\text { instituir relações entre } \\
\text { Estado e sociedade } \\
\text { disseminando o caráter } \\
\text { público do Estado. } \\
\end{array}$ & $\begin{array}{l}\text { Não dispõe de dotação } \\
\text { orçamentária para oferecer } \\
\text { condições adequadas de } \\
\text { participação à maioria dos } \\
\text { conselheiros. }\end{array}$ & $\begin{array}{l}\text { Negociar com os governos a } \\
\text { alocação de recursos } \\
\text { financeiros para possibilitar o } \\
\text { funcionamento adequado dos } \\
\text { conselhos. }\end{array}$ \\
\hline $\begin{array}{l}\text { Possibilidade de maior } \\
\text { democratização do Estado } \\
\text { partilhando decisões entre } \\
\text { governo e sociedade. }\end{array}$ & $\begin{array}{l}\text { Muitos conselhos são } \\
\text { criados pró-forma, para não } \\
\text { funcionar efetivamente. }\end{array}$ & $\begin{array}{l}\text { Processo de acompanhamento } \\
\text { dos conselhos estaduais aos } \\
\text { conselhos municipais com a } \\
\text { sociedade civil. }\end{array}$ \\
\hline $\begin{array}{l}\text { Lugar propício para envolver } \\
\text { a comunidade nos processos } \\
\text { de planejamento e gestão do } \\
\text { município. }\end{array}$ & $\begin{array}{l}\text { Falta vontade política da } \\
\text { maioria dos governantes } \\
\text { para envolver a sociedade } \\
\text { na gestão pública local. }\end{array}$ & $\begin{array}{l}\text { Mobilização da sociedade civil } \\
\text { local, inclusive utilizando } \\
\text { medidas legais, para garantir a } \\
\text { participação nas gestões } \\
\text { públicas. }\end{array}$ \\
\hline $\begin{array}{l}\text { Espaço que possibilita pensar } \\
\text { a política pública universal, } \\
\text { contrapondo-se ao } \\
\text { individualismo e o localismo. }\end{array}$ & $\begin{array}{l}\text { Os conselhos reproduzem } \\
\text { os vícios da cultura política } \\
\text { tradicional. }\end{array}$ & $\begin{array}{l}\text { Avaliação sistemática da prática } \\
\text { e comportamento dos } \\
\text { conselhos e conselheiros, } \\
\text { reforçando os novos valores. }\end{array}$ \\
\hline
\end{tabular}

Fonte: Oliveira (2003, p. 80).

Conforme o autor pontua, esse conjunto de limites indica que a participação da sociedade civil local, por meio dos Conselhos Municipais de Educação - na garantia dos direitos sociais -, no que diz respeito às políticas públicas, apesar dos avanços importantes e significativos, ainda necessita amenizar, abreviar, dirimir os impasses, a 
ALVES, A. V. V.; VIEGAS, E. R. dos S. A participação nos Conselhos Municipais de Educação: entre limitações e potencialidades.

exemplo da baixa capacidade de negociação e de conhecimento das ações a serem empreendidas em prol da efetivação e manutenção do direito à educação; buscar mecanismos que combatam a cultura do "assistencialismo de Estado", em que o serviço público é tido como "um favor" e não um direito do cidadão, pois isso reforça o sentimento de "não pertencimento e/ ou envolvimento" do sujeito com o processo de participação ativa da coisa pública. São necessários investimentos em mobilização e formação dos Conselhos e conselheiros (sujeitos sociais coletivos), no que concerne à formulação e implementação de políticas, que otimizem o funcionamento do aparelho estatal - relação eficiente entre os entes federados e suas obrigações enquanto instância de governo -, tendo em vista a efetiva participação social nos espaços de gestão colegiada.

Apesar do arcabouço normativo-legal brasileiro ter inserido os Conselhos como parte do processo de gestão (descentralizada e participativa), e instituí-los como órgãos normativos, deliberativos e decisórios das políticas públicas, diversas pesquisas/estudos (GOHN, 2000, 2002 e 2011) têm apontado e alertado para o caráter (restrito) apenas consultivo dos Conselhos, cerceando sua atuação - diálogo, debate, aconselhamento, acompanhamento, controle - em matéria de deliberação e decisão.

\section{Considerações finais}

A gestão democrática da educação se constitui em um processo que tem em vista uma orientação de qualidade para a formação humana, tendo como mecanismos a participação social e os Conselhos de Educação, sendo um deles o Conselho Municipal de Educação.

A partir disso, a participação, quando voltada para a democratização da gestão educacional, possibilita o envolvimento coletivo, a descentralização do poder, buscando fazer com que os cidadãos se tornem parte e tomem parte das discussões e decisões tomadas, bem como sejam sujeitos sociais ativos das ações realizadas no âmbito da educação pública. Portanto, a participação no âmbito dos Conselhos Municipais de Educação também tem esse papel, já que se constitui em um elo (CURY, 2006) entre o Estado e a sociedade civil, visando garantir a efetivação de uma educação que atenda aos interesses da sociedade, em específico, dos setores populares, os quais necessitam maiores investimentos em termos de políticas sociais.

Cabe aos Conselhos, conforme afirma o autor, o papel de (re)construir as relações de poder entre os segmentos que compõem o contexto local, estabelecendo novas bases 
ALVES, A. V. V.; VIEGAS, E. R. dos S. A participação nos Conselhos Municipais de Educação: entre limitações e potencialidades.

sobre as quais se explicitem os dissensos e se elaborem consensos ou propostas coletivas para direcionar a ação educacional pública.

A assunção, portanto, dos Conselhos Municipais de Educação, no que concerne à participação e o controle social como órgão ativo na formulação, implementação e avaliação das ações políticas, demanda dos Conselheiros (sujeitos sociais coletivos) uma postura deliberativa que avance no protagonismo consultivo e propositivo de suas funções, para além das intenções unilaterais.

É imperativo, portanto, que se reitere e legitime em todas as instâncias tal postura, como já informava Gohn (2000, p. 182), "os conselhos não podem ser vistos como substitutos da democracia representativa nem como braços auxiliares do executivo ou, ainda, como substitutos da participação popular em geral".

Ainda, em outro momento, a autora (GOHN, 2002) colabora com as nossas considerações ao assinalar alguns pontos que necessitam ser equacionados no sentido de diminuir os entraves no interior dos Conselhos: definir precisamente as competências e atribuições dos Conselhos e da sua relação com o poder legislativo e executivo; zelar pela formulação, elaboração e implementação de instrumentos jurídicos de apoio às suas deliberações e decisões, de forma que estas sejam garantidas; e, por fim, definir e delimitar de forma mais acertada a participação como ação ativa e contínua, destacando o cidadão como sujeito social coletivo do processo.

Em suma, as potencialidades da participação ocupam um espaço maior, sua essência/enraizamento, em grande parte, está no mundo ideal da legislação (CF/1988, LDB/1996 e outros); já seus limites, por outro lado, estão situados no mundo real, tal como explicitado ao longo da análise.

Todavia, acreditamos que a participação pode ser atingida e potencializada a partir da ocupação das instituições, no caso, o Conselho Municipal de Educação, de modo a envolver a comunidade nos processos de planejamento e gestão da educação local com vistas a possibilitar pensar a política pública educacional de forma universal, levando em conta seus interesses, combatendo o localismo, o individualismo, o autoritarismo, o hierarquismo e, assim, a cultura política tradicional; e propiciando uma maior democratização e o controle social sobre a ação do Estado, por meio da partilha de decisões entre governo e sociedade, para além da imposição da legislação. 


\section{Referências}

ALVES, A. V. V. Fortalecimento de Conselhos Escolares: propostas e práticas em municípios sul-mato-grossenses. Dourados-MS: Editora da UFGD, 2014.

AZEVEDO, J. L. de. Notas sobre a análise da gestão da educação e da qualidade do ensino no contexto das políticas educativas. RBPAE, Goiânia, v. 27, n. 3, p. 361-588, set./dez. 2011.

BORDIGNON, G. Conselhos Municipais de Educação. In: LIMA, A. B. de. (Org.). CMEs no Brasil - qualidade social e política da educação. Campinas-SP: Alínea Editora, 2017.

BRASIL. Conselho Municipal e suas Articulações com as Políticas Públicas. Diretoria de Fortalecimento Institucional e Gestão Educacional. Florianópolis-SC: MEC/SEB/UFSC, 2008.

BRASIL. Constituição Federal Brasileira. Constituição da República Federativa do Brasil. Senado Federal: Presidência da República, Casa Civil. Brasília-DF: 1988.

BRASIL. Documento-final da Conferência Nacional de Educação: O PNE na articulação do Sistema Nacional de Educação - participação popular, cooperação federativa e regime de colaboração. Brasília-DF: SEB/MEC, 2014. Disponível em: http://portal.mec.gov.br/arquivos/conferencia/documentos/doc_final.pdf. Acesso em: jul. de 2015.

BRASIL. Lei n 0 9.394, de 20 de dezembro de 1996. Estabelece as diretrizes e bases da educação nacional. Presidência da República, Casa Civil, Subchefia para Assuntos Jurídicos. $\quad$ Brasília-DF: $1996 . \quad$ Disponível em: http://www.planalto.gov.br/Ccivil_03/leis/L9394.htm. Acesso em: mar. de 2018.

BRASIL. Lei no 11.274, de 6 de fevereiro de 2006. Presidência da República, Casa Civil, Subchefia para Assuntos Jurídicos. Brasília-DF: 2006. Disponível em: http://www.planalto.gov.br/ccivil_03/_Ato2004-2006/2006/Lei/L11274.htm. Acesso em: jun. de 2017.

BRASIL. Lei no 12.796, de 4 de abril de 2013. Presidência da República, Casa Civil, Subchefia para Assuntos Jurídicos. Brasília-DF: 2013. Disponível em: http://www.planalto.gov.br/ccivil_03/_ato2011-2014/2013/lei/112796.htm. Acesso em: jun. de 2017.

BRASIL. Lei no13.632, de 6 de março de 2018. Altera a Lei no 9.394, de 20 de dezembro de 1996, para dispor sobre educação e aprendizagem ao longo da vida. Presidência da República,

Casa Civil, Subchefia para Assuntos Jurídicos. Brasília-DF: 2018. Disponível em: http://www.planalto.gov.br/Ccivil_03/_Ato2015-2018/2018/Lei/L13632.htm\#art1.

Acesso em: abr. de 2018. 
CURY, C. R. J. Os conselhos de educação e a gestão dos sistemas. In: FERREIRA, N. S. C.; AGUiAR, M. A. da S. (Orgs.). Gestão da Educação - impasses, perspectivas e compromissos. 5 ed. São Paulo-SP: Cortez Editora, 2006.

GOHN, M. da G. Conselhos gestores na política social urbana e participação popular. Cadernos Metrópole, São Paulo, n. 7, p. 9-31, 1ํo sem. 2002.

GOHN, M. da G. O papel dos conselhos gestores na gestão urbana. In: RIBEIRO, A. C. T (Org.). Repensando la experiencia urbana de América Latina: cuestiones, conceptos y valores. Buenos Aires-ARG: CLACSO, 2000.

GOHN, M. da G. Participação de representantes da sociedade civil na esfera pública na América Latina. Política \& Sociedade, Florianópolis, v. 10, n. 18, p. 223-244, abr. 2011.

GRACINDO, R. V. Gestão democrática nos sistemas e na escola. Brasília: UNB, 2007. LIMA, B. de. Estado, educação e controle social: introduzindo um tema. In: LIMA, B. de. (Org.). Estado e o controle social no Brasil. Uberlândia-MG: EDUFU, 2011.

MOTTA, F. C. P. Administração e participação: reflexos para a educação. Revista da Faculdade de Educação, São Paulo, 10 (2), p. 199-206, jul./dez. 1987.

MOTTA, F. C. P. Administração e participação: reflexões para a educação. Educação \& Pesquisa, São Paulo, v. 29, n. 2, p. 369-373, jul./dez. 2003.

NOGUEIRA, M. A. Um Estado para a sociedade civil: temas éticos e políticos da gestão democrática. São Paulo-SP: Cortez, 2004.

OLIVEIRA, F. M. de. Cidadania e Cultura Política no Poder Local. Fortaleza-CE: Fundação Konrad Adenauer, 2003.

PARO, V. H. Gestão democrática da escola pública. São Paulo-SP: Editora afiliada, 2002.

PATEMAN, C. Participação e teoria democrática. Rio de Janeiro-RJ: Paz e Terra, 1992.

SANFELICE, J. L. Prefácio. In: LIMA, A. B. de. (Org.). CMEs no Brasil - qualidade social e política da educação. Campinas-SP: Alínea Editora, 2017. 


\title{
JORNAL DE PoLíticas EducacionaIS

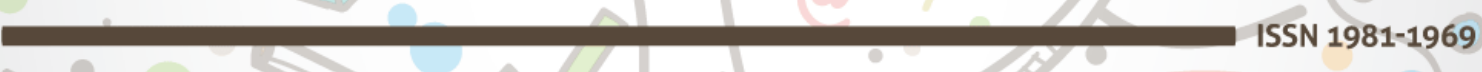 \\ Volume 13 \\ Número 23 \\ 26 de julho de 2019
}

\begin{abstract}
(c)
SORER RIGHIS RESERVED O Copyright é retido pelo/a autor/a (ou primeiro co-autor) que outorga o direito da primeira publicação ao Jornal de Políticas Educacionais. Mais informação da licença de Creative Commons encontra-se em http://creativecommons.org/licenses/by-nc-nd/2.5. Qualquer outro uso deve ser aprovado em conjunto pelo/s autor/es e pelo periódico.

JoRnAl DE Políticas EdUCACIONAIS é uma publicação do Núcleo de Políticas Educacionais do Setor de Educação da Universidade Federal do Paraná - NuPE/UFPR, em consórcio com a Linha de Pesquisa em Políticas Educacionais do Programa de Pós-Graduação em Educação - PPGE/UFPR, que aceita colaboração, reservando-se o direito de publicar ou não o material espontaneamente enviado à redação. As colaborações devem ser enviadas ao NuPE/UFPR, conforme orientações contidas nas páginas do periódico na internet: http://revistas.ufpr.br/ipe.
\end{abstract}

\author{
Indexação: \\ BBE - Biblioteca Brasileira de Educação (MEC/INEP) \\ Clase (Base de Datos Bibliográfica de Revistas de Ciencias Sociales y Humanidades) \\ Diadorim - Diretório de Política de Acesso Aberto das Revistas Científicas Brasileiras (IBICT) \\ Google Scholar \\ Index Copernicus \\ Portal de Periódicos (CAPES) \\ SER - Sistema Eletrônico de Revistas da Universidade Federal do Paraná (SER/UFPR) \\ Sumários de Revistas Brasileiras (FUNPEC-RP) \\ DRJI - Directory of Research Journals Indexing
}

(Periódico integralmente disponível apenas em via eletrônica)

\begin{abstract}
Jornal de Políticas Educacionais / Núcleo de Políticas Educacionais da Universidade Federal do Paraná -
\end{abstract} NuPE/UFPR - v.1, n. 1 (1ํㅗ semestre de 2007) - Curitiba: NuPE/UFPR.

Volume 13, número 23 - Julho de 2019

ISSN 1981-1969

1. Educação - Periódicos. 2. Política Educacional - Periódicos. I. NuPE/UFPR

Comitê Editorial:

Elisângela Scaff (UFPR)

Daniela de Oliveira Pires (UFPR)

Ana Lorena Bruel (UFPR)

Conselho Editorial:

Andréa Barbosa Gouveia (UFPR), Ângela Hidalgo (UNICENTRO), Cesar Gernomino Tello (Universidad Nacional TresFebrero, Argentina), Gladys Beatriz Barreyro (USP), Juca Gil (UFRGS), Jefferson Mainardes (UEPG), João Ferreira de Oliveira (UFG), Luiz Souza Júnior (UFPB), Marcos Edgard Bassi (UFSC), Regina 
ALVES, A. V. V.; VIEGAS, E. R. dos S. A participação nos Conselhos Municipais de Educação: entre limitações e potencialidades.

Maria Michelotto (UFPR), Robert Verhine (UFBA), Rosana Cruz (UFPI), Rubens Barbosa Camargo (USP), Sebastián Donoso Díaz (Universidad de Talca, Chile), Taís Moura Tavares (UFPR), Theresa Adrião (UNICAMP), Vera Peroni (UFRGS).

Créditos e Agradecimentos:

Revisão de Língua Portuguesa, Abstract e Resumen: PROGRAMA DE APOIO ÀS PUBLICAÇÕES CIENTÍFICAS PERIÓDICAS DA UFPR

Arte e diagramação: TIAGO TAVARES (iagotav@gmail.com)

Jornal de Políticas Educacionais

Universidade Federal do Paraná

Setor de Educação

Núcleo de Políticas Educacionais - NuPE/UFPR

Avenida Sete de Setembro, 2645

$2^{\circ}$ andar, Sala 213

80.230-010 - Curitiba - PR - Brasil

Tel.: 41-3535-6264

jpe@ufpr.br

http://revistas.ufpr.br/jpe 